\title{
TIBIOTALOCALCANEAL ARTHRODESIS WITH LATERAL COMPRESSION PLATE
}

\section{ARTRODESE TIBIO-TALO-CALCANEANA COM PLACA DE COMPRESSÃO LATERAL}

Michael J. Coughlin', Caio Nery², Daniel Baumfeld ${ }^{3}$, James Jastifer ${ }^{4}$

\section{ABSTRACT}

Objective: The objective of this study was to evaluate the short-term clinical and radiographic results from a TTC fusion procedure using a lateral locking plate specifically designed for this purpose. Methods: All the fourteen patients were evaluated using a variety of methods, including a visual analogue scale (VAS), the AOFAS hindfoot score and a subjective satisfaction scale. The average follow-up was 10 months. Results: The average AOFAS score improved from 41 points preoperatively to 63 points postoperatively. The VAS pain score decreased from 7 to 3 points. Four patients reported excellent results, eight good, one fair and one poor. Conclusion: Our study provides support for using a specially designed plate for TTC fusion in hindfoot salvage surgery.

Keywords - Arthrodesis; Subtalar Joint; Bone Nails; Calcaneus

\section{RESUMO}

Objetivo: O propósito deste estudo é avaliar os resultados clínicos e radiológicos a curto prazo do procedimento de fusão tíbio-talo-calcaneana (TTC) com o uso de uma placa lateral bloqueada especificamente concebida para este fim. Métodos: Todos os 14 pacientes foram avaliados usando uma variedade de métodos, incluindo a escala analógico visual da dor (EAV), escore da AOFAS para o retropé e escala subjetiva de satisfação. $O$ acompanhamento médio foi de 10 meses. Resultados: $O$ escore AOFAS médio melhorou de 41 pontos no periodo pré-operatório para 63 pontos no período pós-operatório. O escore da dor (EAV) caiu de 7 para 3 pontos. Quatro pacientes foram classificados como excelentes resultados, oito bons, um moderado e um ruim. Conclusão: Nosso estudo dá suporte ao uso da placa especialmente desenhada para a fusão tibio-talo-calcaneana (TTC) nas cirurgias de salvamento do retropé.

Descritores - Artrodese; Articulação Talocalcânea; Pinos Ortopédicos; Calcâneo

\section{INTRODUCTION}

Patients with arthritis of the ankle and subtalar joints can have pain and dysfunction with significant alteration of gait and limitation of daily activities. Combined disease of the hindfoot and ankle joints is commonly seen in patients with diabetic Charcot neuroarthropathy, neuromuscular disease, post-traumatic arthritis, talar osteonecrosis, and inflammatory arthritis ${ }^{(1)}$.

The orthopaedic treatment of ankle and subtalar joint disease for which conservative management has failed includes combined tibiotalocalcaneal (TTC) arthrodesis, fusion of the subtalar joint with replacement of the ankle, or joint distraction of the ankle joint with subtalar joint arthrodesis ${ }^{(1-4)}$.

TTC arthrodesis was first described in 1906 (reported by Mendicino) ${ }^{(5)}$ and continues to be a powerful option in dealing with complex deformities and revisions surgeries and is currently the standard of care for this condition ${ }^{(5,6)}$.

Obtaining adequate surgical fixation during TTC arthrodesis may improve outcomes, but can be challenging.

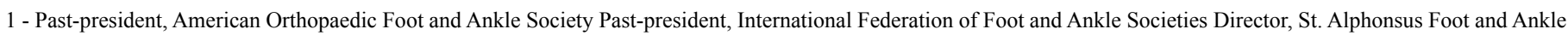
Clinic - Boise, USA.

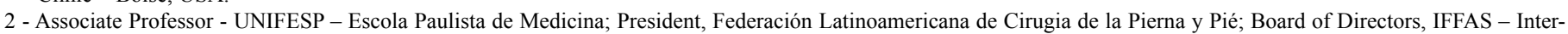
national Federation of Foot and Ankle Societies; Past-president, ABTPé - Associação Brasileira de Tornozelo e Pé - São Paulo, SP, Brazil.

3 - Foot and Ankle Surgeon - Hospital Felício Rocho -Belo Horizonte, MG, Brazil.

4 - Foot and Ankle Surgeon - Michigan State University Kalamazoo Center of Medical Studies - Kalamazoo, USA.

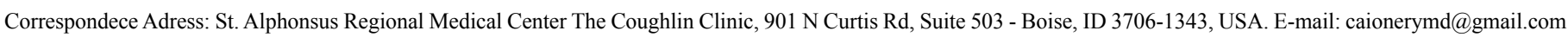
Trabalho realizado no St. Alphonsus Regional Medical Center The Coughlin Clinic - Boise, USA.

Trabalho recebido para publicação: 02/09/2011, aceito para publicação: 25/10/2011.

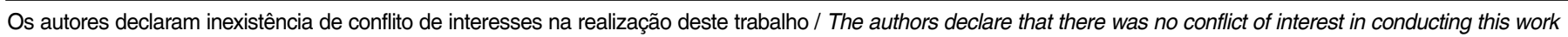


In addition to biomechanical stability, factors that may contribute to successful outcomes after TTC arthrodesis include maintenance of anatomic alignment, techniques that are easily reproducible, and preservation of surrounding soft tissues and blood supply ${ }^{(2,7)}$.

Unfortunately, nonunion rates of $15 \%$ and higher have been reported in the literature following TTC arthrodesis ${ }^{(2,8)}$. A critical factor when performing these types of salvage procedures is achieving stable fixation with compression of the subtalar and ankle joint ${ }^{(8)}$.

There are many described fixation methods for performing the TTC arthrodesis, including crossed compression screws, intramedullary (IM) fixation, blade plate and locking plates $^{(1,7-10)}$.

However, the use of lateral locking plate for TTC fusion has not been described with a specific plate design that conforms to the lateral portion of the tibiotalocalcaneal surface. Other plate systems are an adaptation of the hardware design for upper extremity or fracture fixation ${ }^{(8,10)}$. The use of lateral locking plates may also be technically easier to apply than either an IM nail or a blade plate for TTC arthrodesis. The use of lateral plate for a TTC fusion can reliably relieve patients symptoms, correct deformity, and provide bony union but still there is no consensus regarding which method of fixation is superior ${ }^{(1,11)}$.

The purpose of this study was to evaluate the clinical and radiographic outcomes of short-term results of the use of intra-operative compression and a lateral locking plate design to obtain a TTC arthrodesis.

\section{MATERIALS AND METHODS}

Fourteen consecutive patients undergoing tibiotalocalcaneal arthrodesis with the Tornier Stabilis Ankle
Arthrodesis Plating System ${ }^{\circledR}$ (Figure 1) were prospectively enrolled in this study between January 2010 and February 2011. Institutional Board approval was first obtained for this study. All procedures were performed by one surgeon (MJC). Inclusion criteria were patients with ankle and subtalar joint involvement and included talar avascular necrosis, degenerative arthritis, equinovarus deformity, failed ankle arthrodesis, failed subtalar arthrodesis, failed TTC fusion, and post - traumatic degenerative arthritis (Figure 2 A-D). No patients carried the diagnosis of Charcot arthropathy or failed ankle replacement (Table 1). Exclusion criteria included

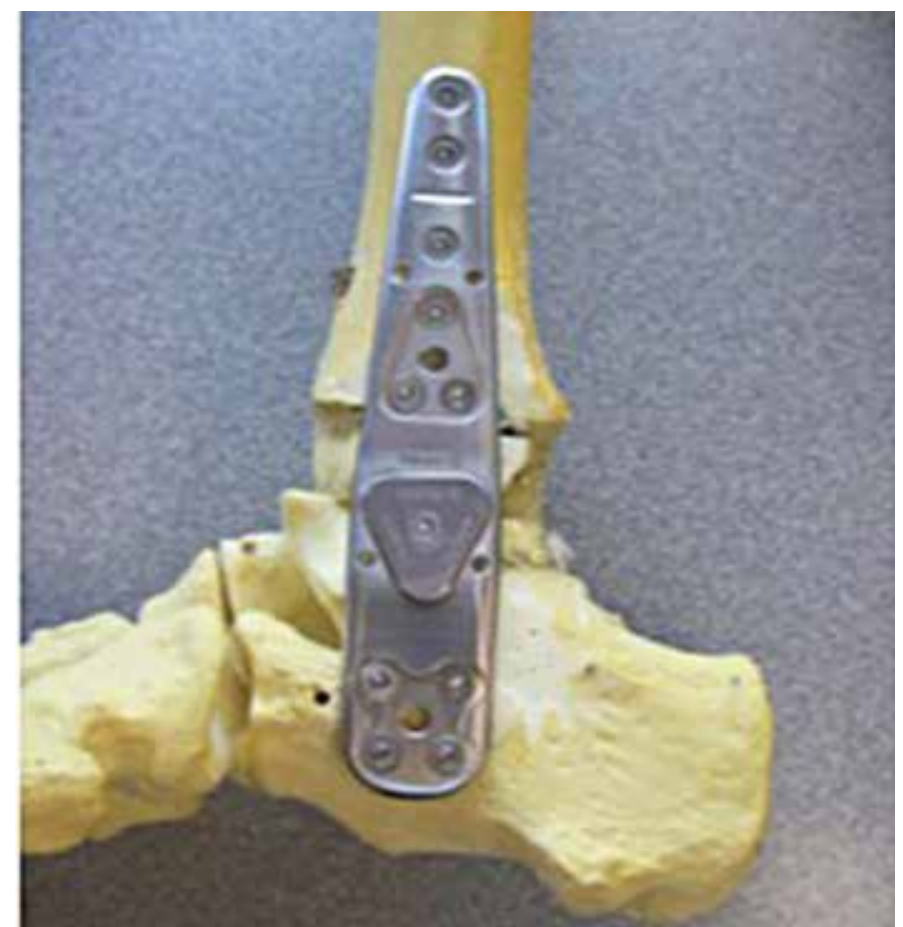

Figure 1 - Lateral view of the Tornier Stabilis Ankle Arthrodesis Plating System ${ }^{\circledR}$ in a sawbone model.

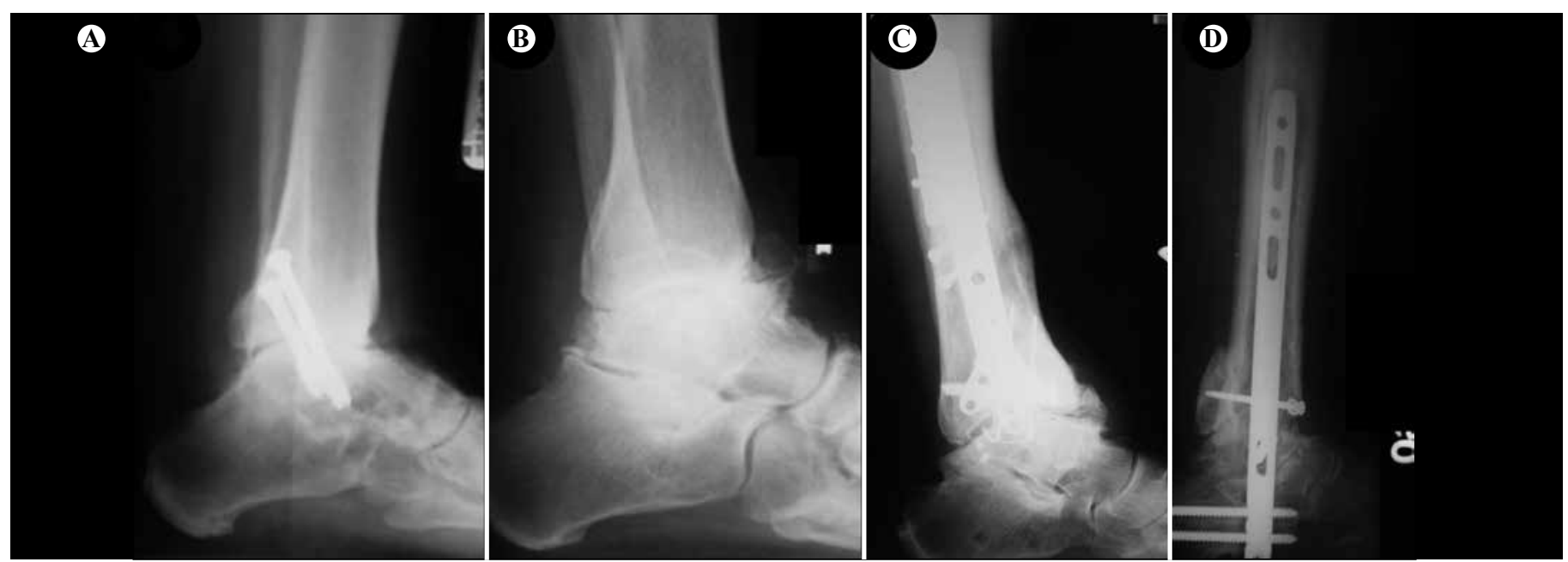

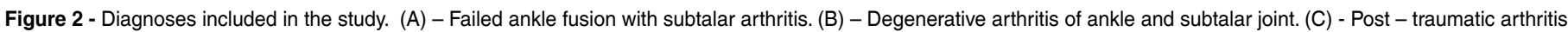
of ankle and subtalar joint. (D) - Failed intramedulary Rod. 
patients with active infections and arthrosis of only one joint. All patients filled out questionnaires preoperatively and using a ten point visual scale, rated their pain on a zero to ten-point scale. They were also evaluated using the AOFAS ankle-hindfoot score ${ }^{(12)}$. The ankle and subtalar joints were assessed radiographically with anteroposterior (AP) and lateral weight bearing film pre and post operatively. The average time of follow up was 10 months (Table 2). 57\% were male and $43 \%$ were female. The right lower extremity was involved in $64 \%$ and the left in $36 \%$ (Table 3 ). The most prevalent disease was post traumatic follow by degenerative disease. As shown in Table 1, 43\% of the patients had no previous attempt at arthrodesis and 29\% had had an ankle arthrodesis with subsequent development of subtalar arthritis. More the $70 \%$ of the patients were obese and 14\% were smokers (Table 3).

Table 1 - Preoperative Analysis.

\begin{tabular}{c|c|c}
\hline Data & $\#$ & $\%$ \\
\hline 2.1. Preoperative Diagnosis & & \\
\hline Paralitic Deformity & 1 & $7 \%$ \\
\hline Post traumatic & 7 & $50 \%$ \\
\hline Degenerative arthritis & 6 & $43 \%$ \\
\hline 2.2. Previous Surgery & & \\
\hline TTC fusion with subtalar non-union & 2 & $14 \%$ \\
\hline Failed ankle fusion & 2 & $14 \%$ \\
\hline Ankle fusion with subtalar arthritis & 4 & $29 \%$ \\
\hline No previous fusion & 6 & $43 \%$ \\
\hline
\end{tabular}

Table 2 - Pre and Post Operative Analysis.

\begin{tabular}{c|c|c|c}
\hline Data & Min & Max & Average \\
\hline Surgery follow up (Months) & 6 & 18 & 10 \\
\hline Pain Score Pre & 4 & 10 & 7 \\
\hline AOFAS Pre & 25 & 54 & 41 \\
\hline Pain score Post & 1 & 7 & 3 \\
\hline
\end{tabular}

Table 3 - Preoperative Demographics.

\begin{tabular}{c|c|c}
\hline Data & $\#$ & $\%$ \\
\hline Male & 8 & $57 \%$ \\
\hline Female & 6 & $43 \%$ \\
\hline Normal weight & 1 & $7 \%$ \\
\hline Overweight & 3 & $21 \%$ \\
\hline Obesity & 10 & $71 \%$ \\
\hline Right & 9 & $64 \%$ \\
\hline Left & 5 & $36 \%$ \\
\hline Smokers & 2 & $14 \%$ \\
\hline Non-smokers & 12 & $86 \%$ \\
\hline Total Patient & 14 & $100 \%$ \\
\hline
\end{tabular}

The patients were clinically evaluated at a minimum of six months following surgery and rated their pain on a zero to ten-point scale. An AOFAS ankle hindfoot score $^{11}$ was also obtained at this evaluation (Table 2). While preoperative AOFAS scoring was calculated out of 100 points, postoperative measurement only allowed a maximum of 86 points. The remaining 14 points were excluded postoperatively as they represent ankle and subtalar motion, which are eliminated after arthrodesis ${ }^{(12)}$.

Patients rated their overall subjective outcomes using a previously published scale. A result was considered excellent if the patient has no problem related to the foot, was very satisfied, has mild or no pain, walked with mild or no difficulty, and would have had the surgery again under similar circumstances. A result was considered good if the patient had a few problems, was satisfied with the result, had mild pain, walked with no or mild difficulty, and would have had the surgery again under similar circumstances. A fair result meant that the patient had moderate pain, some difficulty with walking, and reservations about the success of the surgery. A poor result indicated that the patient had continued pain, had little or no improvement in walking, and regretted having had surgery.

Time to union, quality of bony fusion, and alignment of the TTC arthrodesis were assessed. Observed postoperative complications including the need for further revision surgeries were documented.

\section{Operative Technique TTC}

Surgery was performed with a regional nerve block and general anesthesia in most cases. The patient was positioned supine, with a bump under the ipsilateral hip to internally rotate the ankle to facilitate exposure. A curvilinear lateral incision was made from $10 \mathrm{~cm}$ above the ankle joint extending towards the base of the cuboid allowing the extensor digitorum brevis muscle to be elevated so as to expose the ankle and subtalar joints. The fibula was transected with a beveled cut $8 \mathrm{~cm}$ proximal to the ankle joint, morselized, and used as a bone graft.

The remaining arthritic articular cartilage of the subtalar joint was removed together with the subchondral plate until bleeding bone was seen. A lateral cutting curved guide was applied to the lateral aspect of the tibia and talus, to help with the ankle joint preparation. Bone cuts were made to flatten the lateral surface of the tibia, talus and calcaneus to enable placement of the TTC plate. Soft tissue was released so as to correct any deformity in the alignment (Figure $3 \mathrm{~A}-\mathrm{D})$. After preparation 

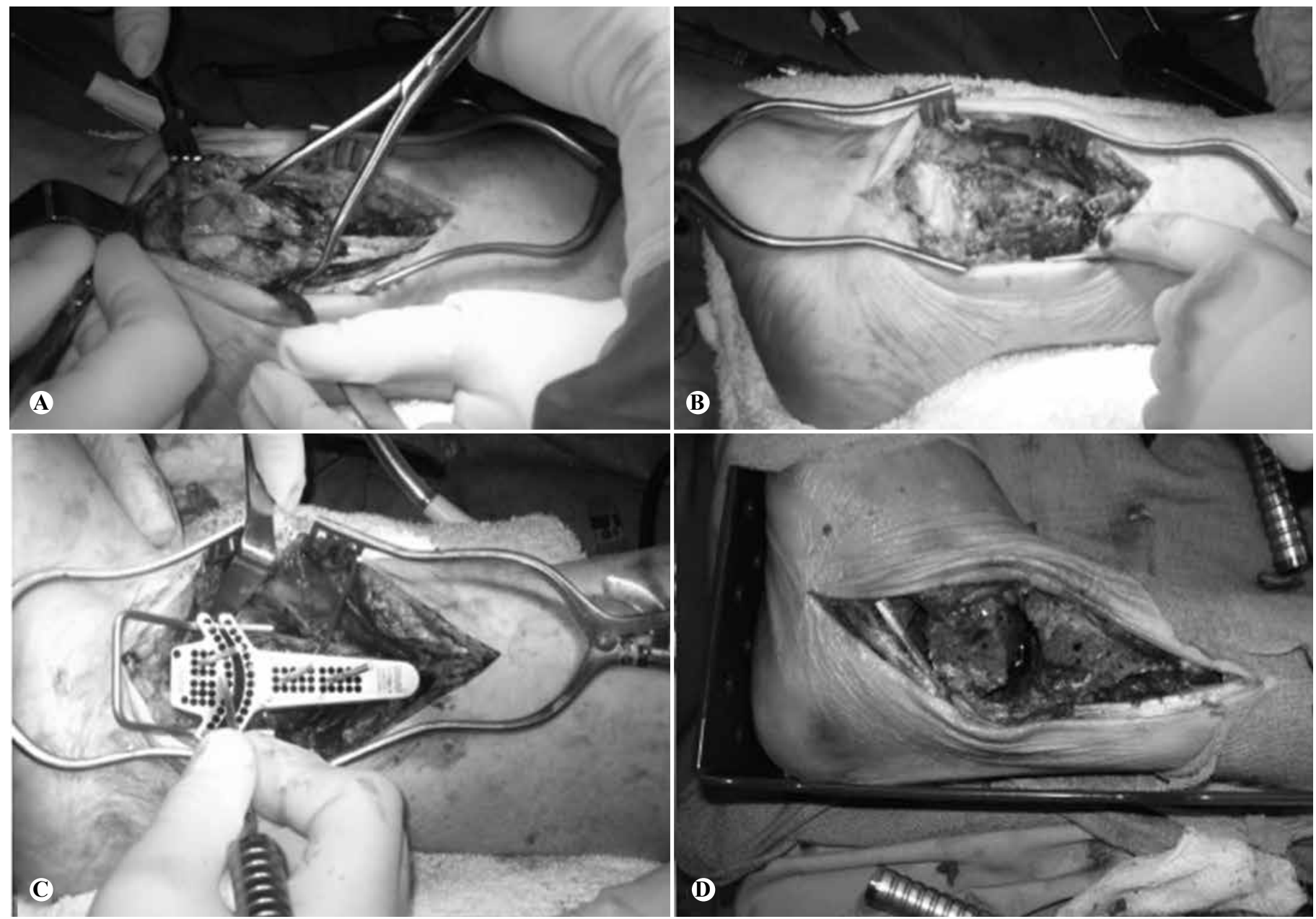

Figure 3 - Surgical Technique. (A) - Fibular resection. (B) - Bone resection to flatten the lateral surface of the tibia, talus and calcaneus. (C) - Ankle cutting curved guide applied to the lateral aspect of the tibia and talus, to assist with the ankle joint preparation. (D) - After preparation of the ankle and subtalar joint surfaces.

of the ankle and subtalar joint surfaces, a $90^{\circ}$ angle foot holding device helps align foot for fusion. Tibiotalocalcaneal Steinman pin was introduced from the heel and drilled in a proximal direction to temporarily hold the arthrodesis position. The TTC plate was positioned and temporarily fixed to the talus. The talus hole guide was used for drilling, and then later insertion of screws. A talar CoverLoc ${ }^{\circledR}$ was then attached to the plate to lock the screws into the plate. Joint compressors were placed both superior and inferior to the subtalar joint (drilled from medial to lateral) to achieve tight intra-operative compression until the plate was fixed to the talus and calcaneus. Calcaneal and talar screws were inserted with the appropriate guide and then a calcaneal CoverLoc ${ }^{\circledR}$ was fixed to the plate. A similar compression technique was then used to compress the tibiotalar joint. The tibia hole guide was used to drill fixation holes and also with the insertion of screws (Figure 4 A-D).

The remaining proximal screw holes were drilled and appropriate screws were inserted.
In performing the TTC arthrodesis, we attempted to position the ankle and the hindfoot in neutral dorsiflexion, 5 degrees of valgus and 10 degrees of external rotation during the joint fixation ${ }^{(1)}$. The wound was closed in layers over a hemovac drain and a below knee splint was then placed.

All patients were admitted to the hospital and later the extremity was placed into a below knee cast on the second postoperative day.

The cast was change every three weeks. Patients were maintained non weight bearing for 6 weeks, followed by another 6 weeks period in a below knee walking cast.

\section{RESULTS}

The average of AOFAS ankle- hindfoot score improved from 41 points preoperatively (range 25 to 54 ) to 63 points postoperatively (range 54 to 69 ). The pain score decreased from 7 points preoperatively (range 4 to 10 ) to 3 points postoperatively (range 1 to 7 ) as demonstrated in Table 2. 

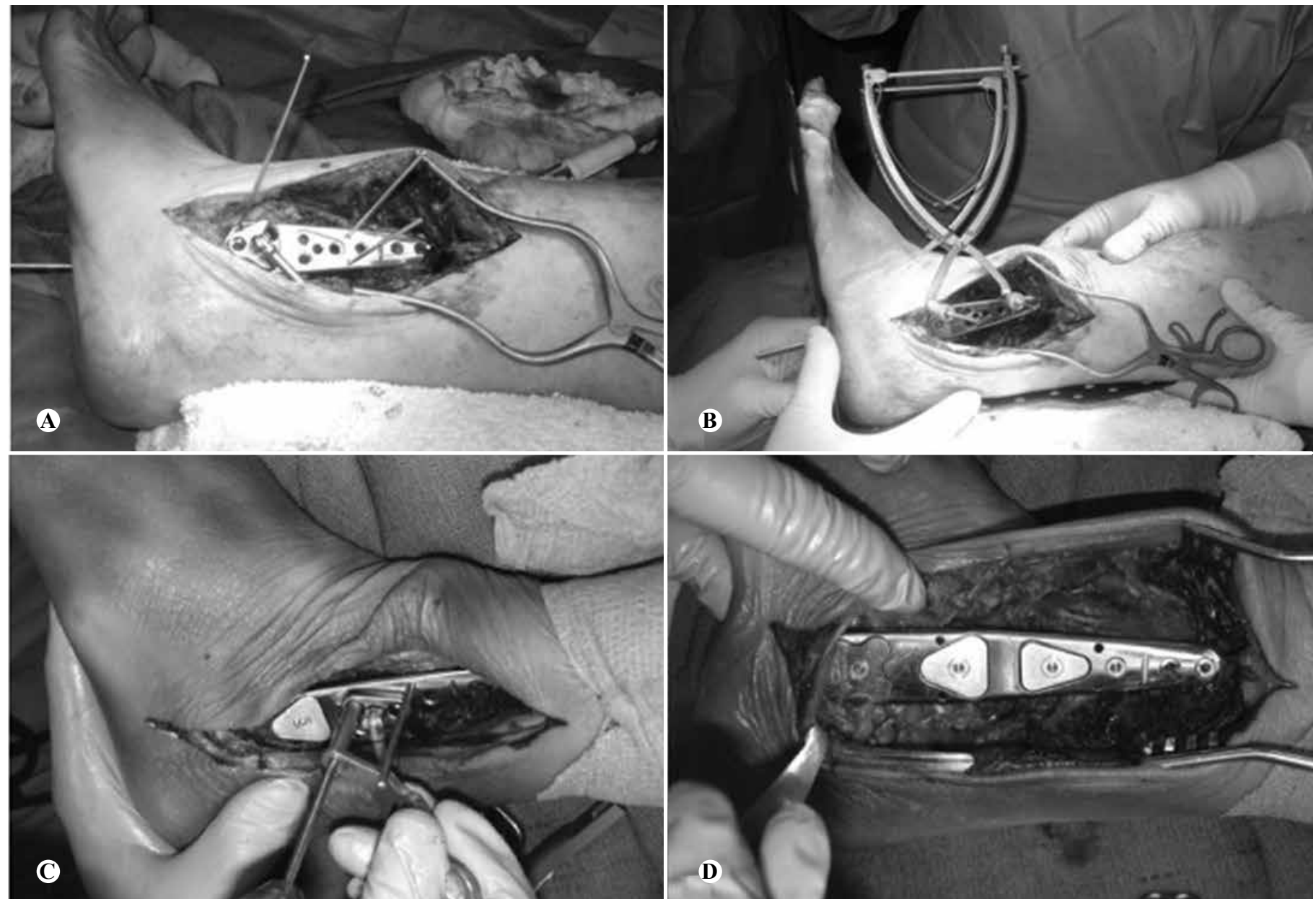

Figure 4 - Surgical Technique. (A) - Tibiotalocalcaneal Steinman pin introduced from the heel to temporarily hold the arthrodesis position and position of the TTC plate. (B) - 90 degrees angle foot holding device to align the foot for fusion; (on posterior aspect of foot and ankle); joint compression clamps compressing the ankle joint. (C) - insertion of the screws after joint compression. (D) - Final position of the TTC plate with CoverLocs ${ }^{\circledR}$ in place.

Thirteen of fourteen patients (93\%) fused radiographically by 6 months (Figure $5 \mathrm{~A}-\mathrm{H}$ ). There was 1 case of infection that developed a nonunion (7\%) and the patient was treated with hardware removal, debridement, antibiotics and external frame implantation.

The overall subjective outcomes rated by the patient shows $57 \%$ of good results, $29 \%$ of excellent results and $7 \%$ of fair or poor results.

\section{DISCUSSION}

Tibiotalocaneal arthrodesis is a salvage surgical procedure used for treatment of end-stage arthrosis and deformity of the ankle and subtalar joints. The goal of the procedure is to obtain a solid, pain-free fusion ${ }^{(1)}$. Until now there has have been no consensus regarding the optimal method of fixation ${ }^{(1,2,3,8)}$. Choices of implants have included screws, locking humeral plates, angled blade plates, external fixation, and intramedullary rods ${ }^{(1,9)}$. We believe the optimal TTC position to achieve a successful result is achieved by placing the ankle and the hindfoot in neutral dorsiflexion/plantarflexion, 5 degrees of valgus and 10 degrees of external rotation during the joint fixation ${ }^{(1)}$.

Locking plate fixation is a relatively new method of fixation for TTC arthrodesis. Recently, Ahmad et al ${ }^{(8)}$ using a proximal humeral locking plate for TTC arthrodesis reported it was predictable in alleviating symptoms, providing bony union, correcting deformity, and restoring and improving function. A fusion rate of $94.4 \%$ was noted at 6 months following surgery.

The advantages of using a locking plate include the following: the creation of a fixed stable construct, limited contact between the plate and bone, reducing stress on periosteal blood flow and a procedure that we believe is less technically demanding than blade plate fixation $^{(8,10)}$. In a cadaveric study, Chodos et al ${ }^{(13)}$ demonstrated that locking plates provided higher initial stiffness and higher torsional load to failure, and lower construct deformation than blade plate fixation for TTC arthrodesis. The authors suggested that multiple distal 


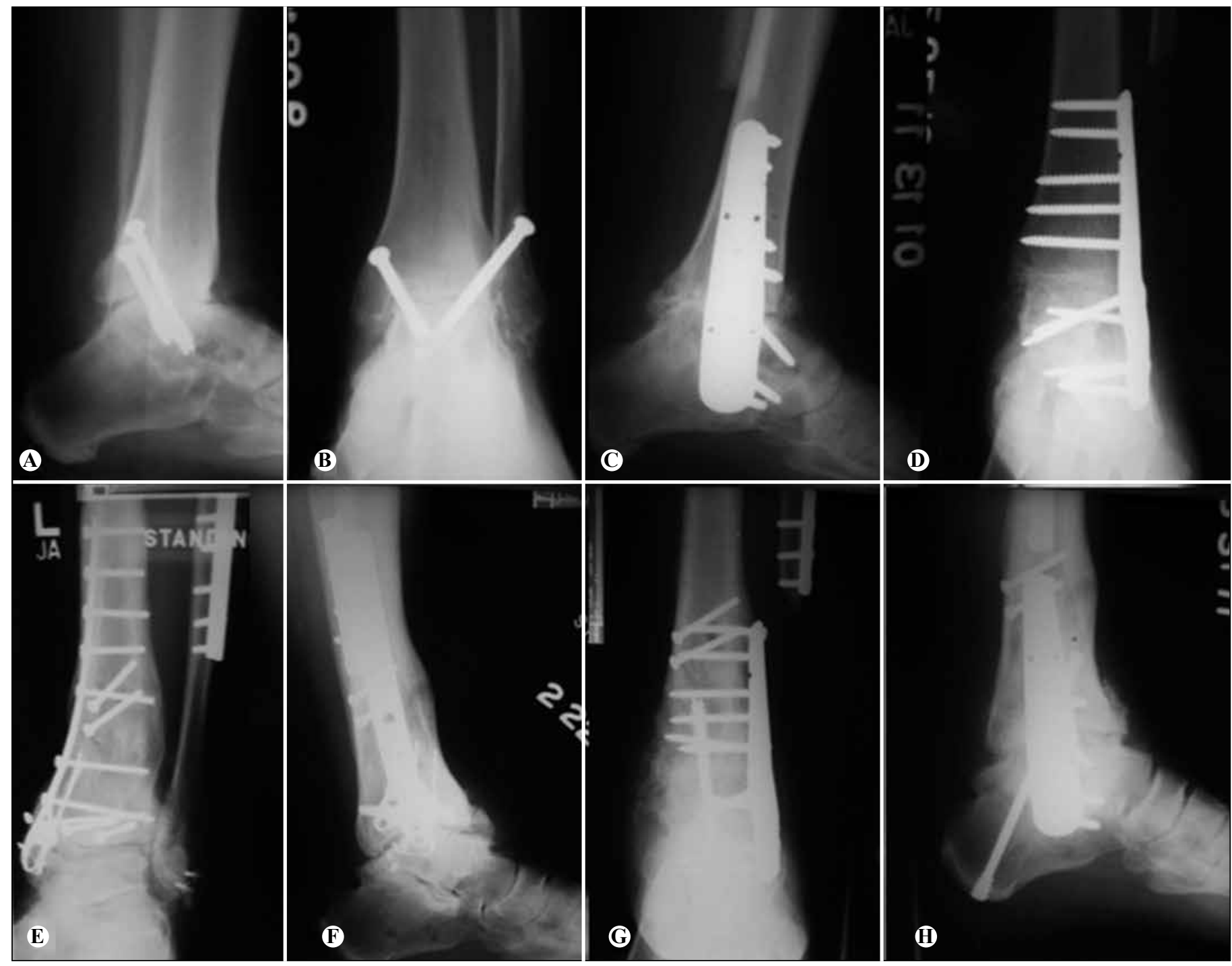

Figure 5 - Preoperative and postoperative radiography showing the plate position and the fused joint. (A-B) - Lateral and AP view of the ankle joint with a fail ankle fusion and subtalar arthritis. (C-D) - Lateral and AP view after 6 months with fused ankle and subtalar joint. (E-F) - Lateral and AP view of ankle with a post traumatic arthritis of the ankle and subtalar joint. (G-H) - Lateral and AP radiography with successful ankle and subtalar fusion after 6 months of the surgery.

locking screws in diverging planes may provide more stability than a fixed angle blade plate construct ${ }^{(13)}$.

Furthermore, O'Neill et al ${ }^{(5)}$ found that locking plate fixation had higher final rigidity than intramedullary fixation and concluded that locking plate fixation can be effectively used for TTC arthrodesis.

Bennett et $\mathrm{al}^{(2)}$ reported that three crossed screws provided more biomechanical stability with regard to micromotion at the arthrodesis site when compared with a locked intramedullary nail with a two crossed screw configuration.

Chiodo et $\mathrm{al}^{(14)}$ compared retrograde intramedullary rod fixation with blade plate fixation augmented with a sagittal plane screw and reported that the blade plate and screw construct was biomechanically superior, especially in osteopenic bone. Although they observed that blade plate fixation is more technically demanding, they recommended the use of blade plate fixation over an intramedullary nail in patients with poor bone quality.

Smith and Coughlin ${ }^{(11)}$, in a previous report, reported a $20 \%$ non-union rate of TTC arthrodesis using a intramedullary rod and noted complete pain relief was difficult to achieve.

We believe that these studies support the concept of internal fixation for tibiotalocalcaneal arthrodesis as an effective alternative to blade plate or intramedullary nail fixation, particularly when a fixed angle locking construct is able to achieve compression at the same time ${ }^{(8,15)}$.

The newer plate design for TTC arthrodesis used in this study provides the advantage of a fixed angle-locking construct while achieving compression across the arthrodesis sites.

We have demonstrated that using a specific locking pla- 
te combined with controlled compression at each joint prior to the placement of internal fixation allowed us to achieve a successful TTC fusion that was predictable in alleviating symptoms, providing bony union, correcting deformity, and restoring and improving function. More than $90 \%$ of patients were healed at six month following surgery.

Patients who had a TTC arthrodesis with the Tournier Stabilis ${ }^{\circledR}$ plate had substantially higher functional and lower pain scores than before surgery. The mean time to fusion was six months and the postoperative AOFAS score improved from 41 points pre-operatively to 63 points postoperatively, which are comparable to those observed in other studies ${ }^{(3-6,8,15-20)}$.

We believe that the high union rate was due a precise surgical technique, the enhance compression that the system provides, the use of fibular grafting combined with a strong locking plate construct

The mean postoperative AOFAS score in our study is consistent with significantly improved pain and function with residual limitations. In our current study, we report the results of a TTC arthrodesis technique with a specific plate design for the treatment of combined subtalar and ankle joint arthritis in patients with other co-mobidities including advanced age, obesity, diabetes and failed prior surgery.

This study does have some inherent limitations, including length of follow-up and population size. As the range of follow up did not exceed 10 month of average, final AOFAS and VAS scores may change in the long term. We intend to follow up on these patients at one year following surgery, and we suggest that their subjective and objective findings will likely be improved over their short term six month information. The limited size of the study population did not allow for statistically significant comparisons between groups of patients.

\section{CONCLUSION}

In conclusion, this study shows that using specific plate design for TTC fusion combined with intraoperative compression of the arthrodesed joints can enhance end results with a less demanding technique.

\section{REFERÊNCIAS}

1. Miller SD. Intramedullary rod versus blade-plate and screw fixation for tibiotalocalcaneal arthrodesis. JBJS Online, December 29, 2003.

2. Bennett GL, Cameron B, Njus G, Saunders M, Kay DB. Tibiotalocalcaneal arthrodesis: a biomechanical assessment of stability. Foot Ankle Int. 2005;26(7):530-6.

3. Mendicino RW, Catanzariti AR, Saltrick KR, Dombek MF, Tullis BL, Statler TK, et al. Tibiotalocalcaneal arthrodesis with retrograde intramedullary nailing. $J$ Foot Ankle Surg. 2004;43(2):82-6.

4. Quill G. Tibiotalocalcaneal and pantalar arthrodesis. Foot Ankle Clin. 1996;1:199-209.

5. O'Neill PJ, Logel KJ, Parks BG, Schon LC. Rigidity comparison of locking plate and intramedullary fixation for tibiotalocalcaneal arthrodesis. Foot Ankle Int. 2008;29(6):581-6.

6. Russotti GM, Johnson KA, Cass JR. Tibiotalocalcaneal arthrodesis for arthritis and deformity of the hind part of the foot. J Bone Joint Surg Am. 1988;70(9):1304-7.

7. Mann MR, Parks BG, Pak SS, Miller SD. Tibiotalocalcaneal arthrodesis: a biomechanical analysis of the rotational stability of the Biomet Ankle Arthrodesis Nail. Foot Ankle Int. 2001;22(9):731-3.

8. Ahmad J, Pour AE, Raikin SM. The modified use of a proximal humeral locking plate for tibiotalocalcaneal arthrodesis. Foot Ankle Int. 2007;28(9):977-83.

9. Berson L, McGarvey WC, Clanton TO. Evaluation of compression in intramedullary hindfoot arthrodesis. Foot Ankle Int. 2002;23(11):992-5.

10. Lowery NJ, Joseph AM, Burns PR. Tibiotalocalcaneal arthrodesis with the use of a humeral locking plate. Clin Podiatr Med Surg. 2009;26(3):485-92.

11. Smith B, Coughlin MJ. Tibiotalocalcaneal arthrodesis with a retrograde intramedulary nail. Rev ABTPe. 2007;1:9-12.
12. Kitaoka HB, Alexander IJ, Adelaar RS, Nunley JA, Myerson MS, Sanders M. Clinical rating systems for the ankle-hindfoot, midfoot, hallux, and lesser toes. Foot Ankle Int. 1994;15(7):349-53.

13. Chodos MD, Parks BG, Schon LC, Guyton GP, Campbell JT. Blade plate compared with locking plate for tibiotalocalcaneal arthrodesis: a cadaver study. Foot Ankle Int. 2008;29(2):219-24.

14. Chiodo CP, Acevedo JI, Sammarco VJ, Parks BG, Boucher HR, Myerson MS, et al. Intramedullary rod fixation compared with blade-plate-and-screw fixation for tibiotalocalcaneal arthrodesis: a biomechanical investigation. J Bone Joint Surg Am. 2003;85(12):2425-8.

15. Papa JA, Myerson MS. Pantalar and tibiotalocalcaneal arthrodesis for post-traumatic osteoarthrosis of the ankle and hindfoot. J Bone Joint Surg Am. 1992;74(7):1042-9.

16. Goebel M, Gerdesmeyer L, Mückley T, Schmitt-Sody M, Diehl P, Stienstra J,et al. Retrograde intramedullary nailing in tibiotalocalcaneal arthrodesis: a short-term, prospective study. J Foot Ankle Surg. 2006;45(2):98-106.

17. Alvarez RG, Barbour TM, Perkins TD. Tibiocalcaneal arthrodesis for nonbraceable neuropathic ankle deformity. Foot Ankle Int. 1994;15(7):354-9.

18. Berend ME, Glisson RR, Nunley JA. A biomechanical comparison of intramedullary nail and crossed lag screw fixation for tibiotalocalcaneal arthrodesis. Foot Ankle Int. 1997;18(10):639-43.

19. Hanson TW, Cracchiolo A 3rd. The use of a 95 degree blade plate and a posterior approach to achieve tibiotalocalcaneal arthrodesis. Foot Ankle Int. 2002;23(8):704-10.

20. Jones CP, Coughlin MJ, Shurnas PS. Prospective CT scan evaluation of hindfoot nonunions treated with revision surgery and low-intensity ultrasound stimulation. Foot Ankle Int. 2006;27(4):229-35. 